\title{
Application of Multiwalled Carbon Nanotube Nanofluid for 450 W LED Floodlight
}

\author{
Bui Hung Thang, ${ }^{1}$ Le Dinh Quang, ${ }^{1}$ Nguyen Manh Hong, ${ }^{1,2}$ \\ Phan Hong Khoi, ${ }^{2}$ and Phan Ngoc Minh ${ }^{1,2}$ \\ ${ }^{1}$ Institute of Materials Science (IMS), Vietnam Academy of Science and Technology, A2 Building, 18 Hoang Quoc Viet Road, \\ Cau Giay District, Hanoi 122102, Vietnam \\ ${ }^{2}$ Center for High Technology Development (HTD), Vietnam Academy of Science and Technology, 2B Building, \\ 18 Hoang Quoc Viet Road, Cau Giay District, Hanoi 122102, Vietnam
}

Correspondence should be addressed to Bui Hung Thang; thangbh@ims.vast.vn and Phan Ngoc Minh; pnminh@vast.ac.vn Received 28 February 2014; Revised 17 June 2014; Accepted 17 June 2014; Published 1 July 2014

Academic Editor: Jinlong Jiang

Copyright (C) 2014 Bui Hung Thang et al. This is an open access article distributed under the Creative Commons Attribution License, which permits unrestricted use, distribution, and reproduction in any medium, provided the original work is properly cited.

Overheating of the high-power light emitting diode (LED) has a dramatic effect on the chip's lifetime. Heat dissipation for highpower LED is becoming a major challenge for researchers and technicians. Compared with the air cooling method, the liquid cooling method has many advantages and high efficiency because of higher specific heat capacity, density, and thermal conductivity. Carbon nanotubes with remarkable thermal properties have been used as additives in liquids to increase the thermal conductivity. In this work, multiwalled carbon nanotubes nanofluid (MWCNTs nanofluid) was used to enhance heat dissipation for $450 \mathrm{~W}$ LED floodlight. MWCNTs nanofluid was made by dispersing the $\mathrm{OH}$ functionalized MWCNTs in ethylene glycol/water solution. The concentration of MWCNTs in fluid was in the range between 0.1 and 1.3 gram/liter. The experimental results showed that the saturated temperature of $450 \mathrm{~W}$ LED chip was $55^{\circ} \mathrm{C}$ when using water/ethylene glycol solution in liquid cooling system. In the case of using MWCNTs nanofluid with 1.2 gram/liter of MWCNTs' concentration, the saturated temperature of LED chip was $50.6^{\circ} \mathrm{C}$. The results have confirmed the advantages of the MWCNTs for heat dissipation systems for high-power LED floodlight and other high power electronic devices.

\section{Introduction}

In recent years, the problem of heat dissipation with features and strengthening functions of products has become more significant. Many approaches can improve the cooling system performance. The most feasible one is to enhance the heat transfer (dissipation) performance through the working fluid without modifying the mechanical designs or key components of the system. Recent studies have shown that the thermal conductivity of the suspension which contains suspended metallic or nonmetallic nanoparticles can be much higher than that of the base fluid, and it was called as "nanofluid" $[1,2]$. On this basis, adding certain kinds of nanomaterials into base fluid is considered to be a novel approach to enhance the thermal conductivity in heat transfer medium [3]. Results showed that the thermal conductivity enhancements of nanofluids could be influenced by multifaceted factors including the volume fraction of nanoparticles, the tested temperature, thermal conductivity of the base fluid, nanoparticles size, pretreatment process, and the additives of the fluids $[4,5]$.

Carbon nanotubes (CNTs) have attracted much attention because of their unique structure and remarkable mechanical, thermal, and electrical properties [6-10]. CNTs have been used as additives in liquids to increase the thermal conductivity, one of the most important issues in industry [11]. Owing to their very high thermal conductivity $(2000 \mathrm{~W} / \mathrm{m} \cdot \mathrm{K}$ compared to thermal conductivity of $\mathrm{Ag} 419 \mathrm{~W} / \mathrm{m} \cdot \mathrm{K})[12,13]$, CNTs become one of the most suitable nanoadditives to fabricate the nanofluid for thermal dissipation in many industrial 


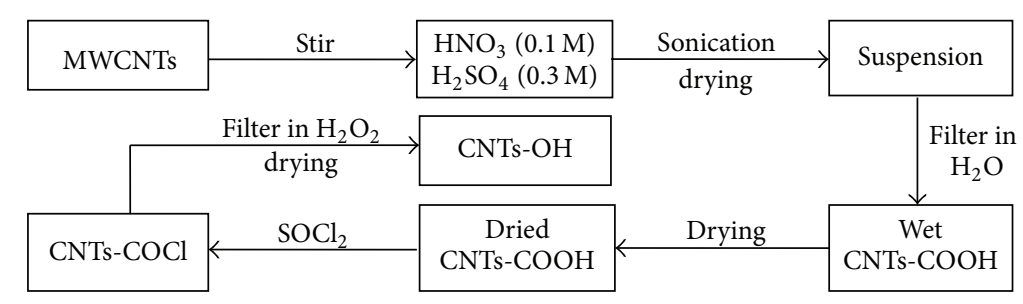

FIGURE 1: Process for functionalization of the MWCNTs with hydroxyl functional group.

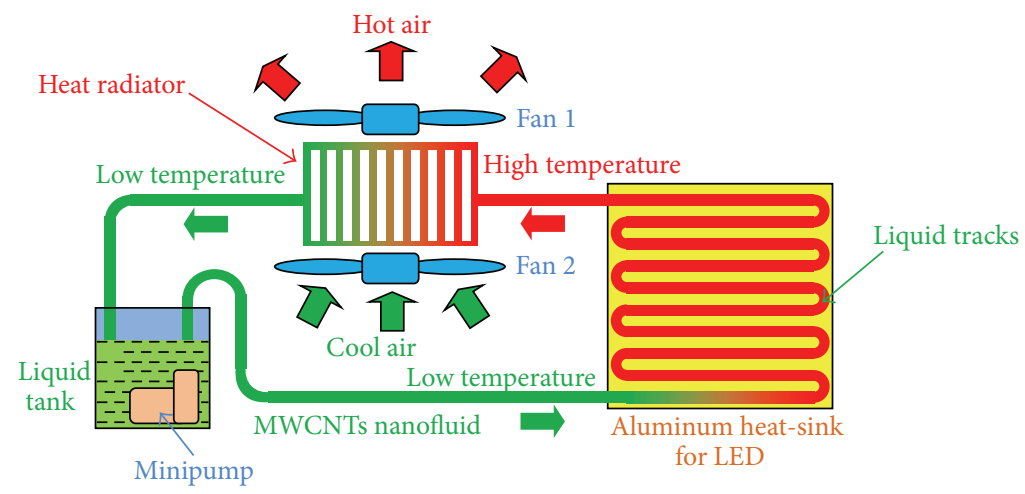

FIGURE 2: Scheme of cooling system using MWCNTs nanofluid for $450 \mathrm{~W}$ LED floodlight.

and consumer products $[14,15]$. In this paper, we present the results on application of multiwalled carbon nanotube nanofluid (MWCNTs nanofluid) for $450 \mathrm{~W}$ LED floodlight.

\section{Experiment}

MWCNTs were produced at the IMS by thermal CVD technique on solid catalyst in a gas mixture of acetylene, hydrogen, and nitrogen. The diameter and length of the grown MWCNTs were in the range $15 \mathrm{~nm}-90 \mathrm{~nm}$ and several ten $\mu \mathrm{m}$, respectively [16]. The stability of carbon nanotubes in fluids can be increased by introducing hydroxyl groups onto the surface of CNTs [17].

Process for functionalization of the MWCNTs with hydroxyl functional group $(-\mathrm{OH})$ was shown in Figure 1 with the following steps [16].

Step 1. MWCNTs were treated in the mixture of hot acid $\left(\mathrm{HNO}_{3}: \mathrm{H}_{2} \mathrm{SO}_{4}\right.$ in ratio $\left.1: 3\right)$ at $60^{\circ} \mathrm{C}$ in $6 \mathrm{~h}$.

Step 2. The suspension obtained in Step 1 was dried in argon atmosphere at $80^{\circ} \mathrm{C}$ for $24 \mathrm{~h}$.

Step 3. The mixture obtained in Step 2 was treated in the thionyl chloride $\left(\mathrm{SOCl}_{2}\right)$ to obtain MWCNTs-COCl.

Step 4. The MWCNTs-COCl was filtered in hydrogen peroxide $\left(\mathrm{H}_{2} \mathrm{O}_{2}\right)$ and dried in argon atmosphere at $80^{\circ} \mathrm{C}$ for $24 \mathrm{~h}$ to obtain MWCNTs-OH.
The ethylene glycol/distilled water solution (EG/DW solution) was prepared by heat-magnetic stirring at $50^{\circ} \mathrm{C}$ and $6.5 \mathrm{rps}$ (rounds per second) in 60 minutes. The percent by volume of ethylene glycol in EG/DW solution was $45 \%$. In order to disperse MWCNTs-OH in EG/DW solution, we used the Tween-80 surfactant and Hielscher Ultrasonics vibration instrument. The MWCNTs-OH was dispersed in EG/DW solution with concentration from 0.1 to $1.3 \mathrm{~g} / \mathrm{L}$ to obtain MWCNTs nanofluid. The prepared MWCNTs nanofluid had good stability by using functionalized carbon nanotube and the Tween- 80 surfactant. This was caused by a hydrophobicto-hydrophilic conversion of the surface nature due to the generation of a hydroxyl group, and the Tween-80 surfactant provides lower surface tension of liquids and increases immersion of CNTs [17-19].

We develop a heat dissipation system using MWCNTs nanofluid for a $450 \mathrm{~W}$ LED floodlight. Figure 2 is the schematic view of the heat dissipation system for $450 \mathrm{~W}$ LED floodlight using the MWCNTs nanofluid.

In Figure 2, the aluminum heat-sink was set to directly contact the 9 LED chips; the tracks inside the aluminum heat-sink were fabricated to allow fluid flows through it and absorb heat from the LED chips. The MWCNTs nanofluid was pumped into the aluminum heat-sink with $3 \mathrm{~cm}^{3} / \mathrm{s}$ of flow rate. The pump power consumption of cooling system was $1.8 \mathrm{~W}$. The dimension and power consumption of fan were $120 \times 120 \times 38 \mathrm{~mm}$ and $3.6 \mathrm{~W}$, respectively. The volume of the liquid tank was $500 \mathrm{~mL}$. The heat radiator was made by aluminum material, and dimensions of heat radiator were 


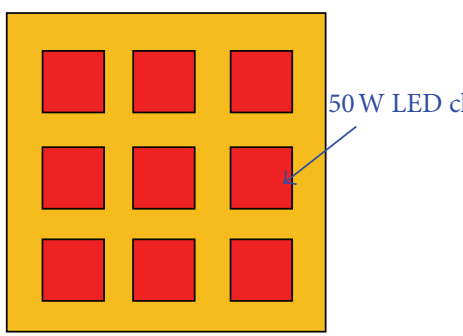

(a)

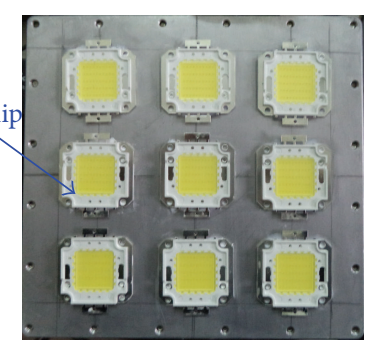

(b)
FIGURE 3: Scheme (a) and real image (b) of aluminum heat-sink with 9 LED chips.

$150 \times 120 \times 25 \mathrm{~mm}$, respectively. Figure 3 is scheme and real image of 9 LED chips, which were mounted on the aluminum heat-sink. The dimension of aluminum heat-sink and LED chip was $210 \mathrm{~mm} \times 210 \mathrm{~mm} \times 17 \mathrm{~mm}$ and $40 \mathrm{~mm}$ $\times 40 \mathrm{~mm} \times 3 \mathrm{~mm}$, respectively. The powers of LED chip and power consumption of LED floodlight were $50 \mathrm{~W}$ and $450 \mathrm{~W}$, respectively.

The environmental temperature was kept at $20^{\circ} \mathrm{C}$ for all measurements by using air conditioner. The temperature of LED chip was directly measured by using an attached temperature sensor and WH7016E Electronic Digital Temperature Controller.

\section{Results and Discussions}

The existence of carboxyl $(\mathrm{COOH})$ and hydroxyl $(\mathrm{OH})$ functional groups bonded to the ends and sidewalls of the CNTs was demonstrated by Raman and Fourier transform infrared (FTIR) spectra. Raman scattering is a powerful technique to probe the changes of surface and structure of MWCNTs. The Raman scattering spectra were clearly seen such that the two bands around 1583.10 and $1333.69 \mathrm{~cm}^{-1}$ in the spectra were assigned to the tangential mode (Gband) and the disorder mode (D-band), respectively. The $\mathrm{D}$ band intensity was increased in the functionalized MWCNTs compared to pristine MWCNTs. The peak intensity ratio $\left(\mathrm{I}_{\mathrm{D}} / \mathrm{I}_{\mathrm{G}}\right)$ at $\mathrm{D}$-band and $\mathrm{G}$-band of 0.99 and 1.87 corresponding to MWCNTs-COOH and MWCNTs-OH exceeded those of pristine MWCNTs $\left(\mathrm{I}_{\mathrm{D}} / \mathrm{I}_{\mathrm{G}}=0.79\right)$. The intensity ratio of $\mathrm{D}$ lines and $G$ lines is different, suggesting some changes of the surface and structure of MWCNTs. This result indicates that some of the $\mathrm{sp}^{2}$ carbon atoms $(\mathrm{C}=\mathrm{C})$ were converted to $\mathrm{sp}^{3}$ carbon atoms $(\mathrm{C}-\mathrm{C})$ at the surface of the MWCNTs after the acid treatment in $\mathrm{HNO}_{3} / \mathrm{H}_{2} \mathrm{SO}_{4}$. The intensity ratio of MWCNTs-OH is higher than that of MWCNTs-COOH indicating that by two chemical treatment processes, the new defects were formed on the surface of MWNCTs [20].

The typical FTIR spectrum of MWCNTs-COOH shows some important peak after MWCNT was treated by mixture of $\mathrm{H}_{2} \mathrm{SO}_{4}$ and $\mathrm{HNO}_{3}$. The vibration of $\mathrm{O}-\mathrm{H}$ bonding in carboxyl group was shown on peak $3431.81 \mathrm{~cm}^{-1}$. It expanded more than that of $\mathrm{O}-\mathrm{H}$ bonding of $\mathrm{H}_{2} \mathrm{O}$. Peak $1707.31 \mathrm{~cm}^{-1}$

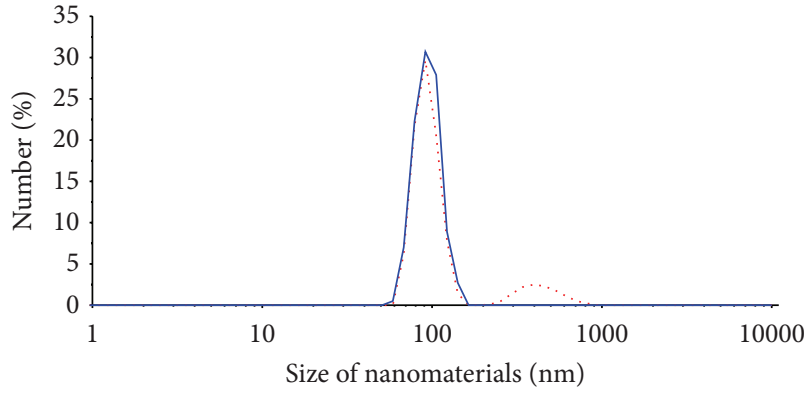

(a)

$---(b)$

FIGURE 4: Spectra of the MWCNTs-OH size distribution in EG/DW solutions by number with 10 minutes of ultrasonication time: (a) immediately after the sonication; (b) 72 hours after the sonication.

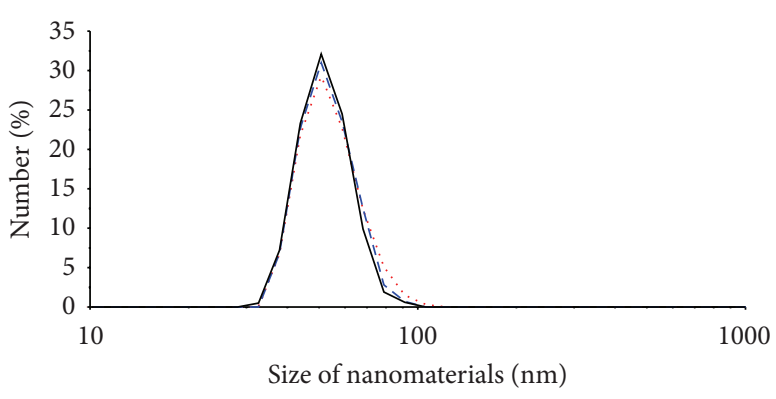

(a)

(b)

$-(\mathrm{c})$

FIGURE 5: Spectra of the MWCNTs-OH size distribution in EG/DW solutions by number after 72 hours from the sonication: line (a) 20 minutes of sonication; line (b) 30 minutes of sonication; line (c) 40 minutes of sonication.

showed the existence of vibration of $\mathrm{C}=\mathrm{O}$ bonding in carboxyl group. This exhibits the importance of proving the existence of carboxyl $(\mathrm{COOH})$ functional groups that appeared due to the oxidation resulting from nitric and sulfuric acids. It clearly shows that the kinds of acids functionalized the surface of MWCNTs. The FTIR transmittance spectra of MWCNTs-OH show that the peak of conjugated $\mathrm{O}-\mathrm{H}$ stretching vibration mode appeared at $3431.81 \mathrm{~cm}^{-1}$, and the central position of $\mathrm{O}-\mathrm{H}$ peak shifted to a lower frequency as well; the expansion of vibration peak and the disappearance of vibration peak of $\mathrm{C}=\mathrm{O}$ bonding at $1707.31 \mathrm{~cm}^{-1}$ indicated the generation of hydroxyl groups on surface of MWCNTs [20].

In order to evaluate the dispersion of MWCNTs-OH in EG/DW solutions, we used the Malvern Zetasizer Nano ZS Instrument. Figure 4 is the spectra of the MWCNTs$\mathrm{OH}$ size distribution in EG/DW solutions by number with 10 minutes of ultrasonication. Line (a) in Figure 4 showed that immediately after the ultrasonication, the MWCNTs$\mathrm{OH}$ was still gathering into large bundles with two peaks at $437 \mathrm{~nm}$ and $93.5 \mathrm{~nm}$. The $437 \mathrm{~nm}$ peak was corresponding 


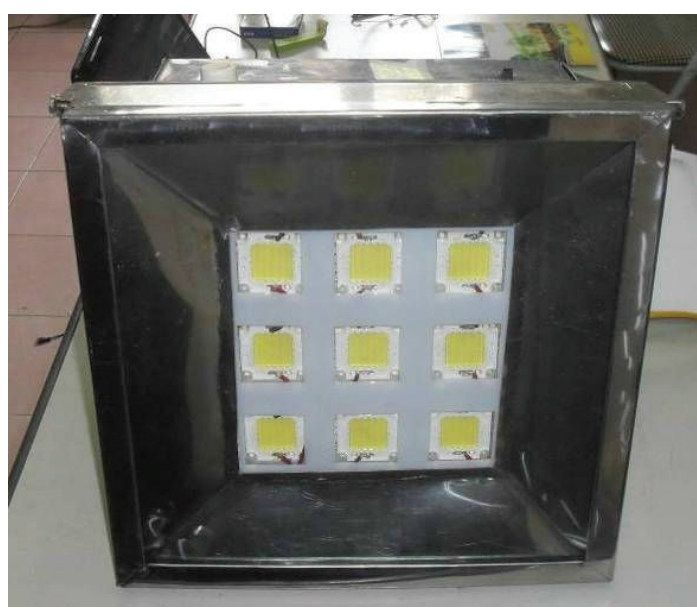

(a)

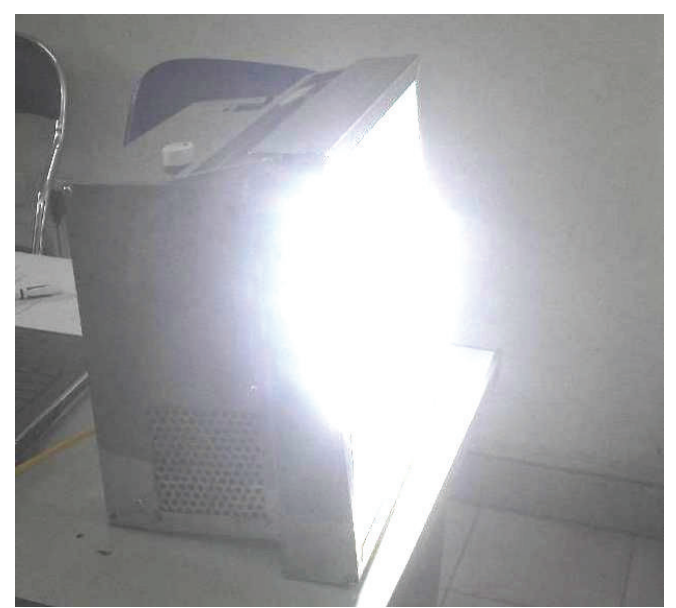

(b)

FIGURE 6: The $450 \mathrm{~W}$ LED floodlight using MWCNTs nanofluid for heat dissipation.

to the large bundles of MWCNTs-OH, whereas the $93.5 \mathrm{~nm}$ peak was corresponding to the individual of the MWCNTs$\mathrm{OH}$ in EG/DW solutions. In order to remove large bundles from EG/DW solutions, the solutions were settled in 72 hours. Line (b) in Figure 4 showed that after 72 hours from the ultrasonication, the $437 \mathrm{~nm}$ peak disappeared, which means that there were no longer large bundles of MWCNTs$\mathrm{OH}$ in EG/DW solutions. However, the MWCNTs were still gathering into small bundles with the size distribution from $70 \mathrm{~nm}$ to $170 \mathrm{~nm}$.

Figure 5 was the spectra of the MWCNTs-OH size distribution in EG/DW solution by number with 20,30 , and 40 minutes of sonication. In the case of 20 minutes of ultrasonic vibration time (showed as line (a) in Figure 5), the spectra of the MWCNTs-OH size distribution by number were from $18 \mathrm{~nm}$ to $95 \mathrm{~nm}$. This result showed that MWCNTs-OH was better dispersed in EG/DW solutions with 20 minutes of ultrasonic vibration time. However, the range of spectra did not match with $15-90 \mathrm{~nm}$ of the diameter of MWCNTs$\mathrm{OH}$. In the case of 30 minutes or 40 minutes of ultrasonic vibration time, the MWCNTs-OH was well dispersed in EG/DW solutions shown as line (b) and line (c) in Figure 5. The spectra of the MWCNTs-OH size distribution by number in line (b) and line (c) matched with $15-90 \mathrm{~nm}$ of the diameter of MWCNTs-OH. The results showed that the ultrasonic vibration time more than 30 minutes is required for well dispersion of MWCNTs-OH in EG/DW solutions, so we chose 30 minutes of ultrasonic vibration time for all subsequent experiments [20].

Figure 6 is the $450 \mathrm{~W}$ LED floodlight using MWCNTs nanofluid for heat dissipation. The experimental results of heat dissipation for the $450 \mathrm{~W}$ LED floodlight with different concentrations of CNTs in nanofluid were shown in Figure 7. The temperature of the LED chip was $20^{\circ} \mathrm{C}$ at initial time, and then the temperature of the LED chip was saturated after 40 minutes of working time. When using water/EG solution for heat dissipation, the saturated temperature of the LED

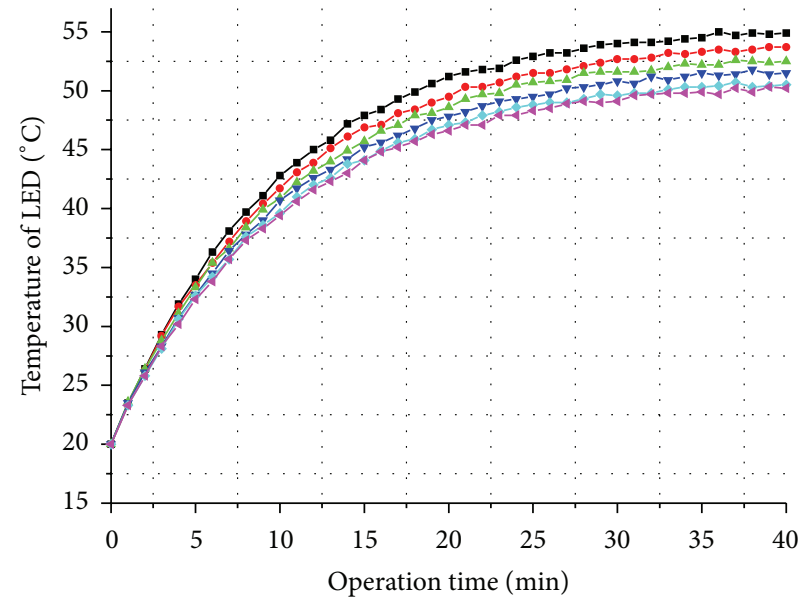

450 W LED flood light

--- Without using CNTs in fluid

- - - Nanofluid with $0.3 \mathrm{~g} / \mathrm{L}$ of CNTs

$-\Delta-$ Nanofluid with $0.5 \mathrm{~g} / \mathrm{L}$ of CNTs

- v- Nanofluid with $0.7 \mathrm{~g} / \mathrm{L}$ of CNTs

- - Nanofluid with $1.0 \mathrm{~g} / \mathrm{L}$ of CNTs

-4 - Nanofluid with $1.2 \mathrm{~g} / \mathrm{L}$ of CNTs

FIGURE 7: The temperature of $450 \mathrm{~W}$ LED floodlight measured as a function of operation time with different concentrations of CNTs in nanofluid.

chip was about $55^{\circ} \mathrm{C}$. The saturated temperature of the LED chip reached $53.7^{\circ} \mathrm{C}, 52.5^{\circ} \mathrm{C}, 51.9^{\circ} \mathrm{C}$, and $50.6^{\circ} \mathrm{C}$ when using nanofluids with $0.3 \mathrm{~g} / \mathrm{L}, 0.5 \mathrm{~g} / \mathrm{L}, 0.7 \mathrm{~g} / \mathrm{L}, 1.0 \mathrm{~g} / \mathrm{L}$, and $1.2 \mathrm{~g} / \mathrm{L}$ of CNTs concentration, respectively. These results indicated that by mixing CNTs- $\mathrm{OH}$ with $1.2 \mathrm{~g} / \mathrm{L}$ of concentration in the nanofluid, the saturated temperature of LED chip decreased by $4.5^{\circ} \mathrm{C}$ compared to fluid without CNTs. According to the datasheet of the LED chip, if the operating temperature drops $10^{\circ} \mathrm{C}$ the lifetime of LED chips increases approximately 


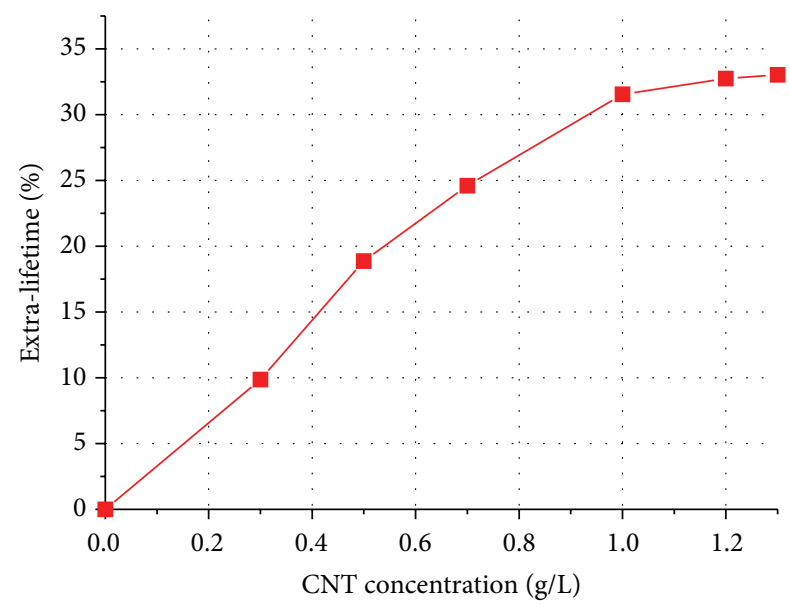

FIgURE 8: The dependence of extra-lifetime percent of $450 \mathrm{~W}$ LED on CNTs concentration in nanofluid.

2 times. Thus, the lifetime of LED was estimated as the following expression:

$$
L \simeq L_{0} \cdot 2^{\Delta t / 10}
$$

where $L_{0}, L$, and $\Delta t$ indicated the basic-lifetime, the extended-lifetime, and the temperature reduction of LED, respectively. Thus, the extra-lifetime percent of LED is determined by the expression:

$$
\% L=\frac{L-L_{0}}{L_{0}} \cdot 100 \%=\left(2^{\Delta t / 10}-1\right) \cdot 100 \% .
$$

From (2), the extra-lifetime percent of LED was estimated as shown in Figure 8. It clearly showed that the lifetime of LED is extended when the CNTs concentration is increased. The extra-lifetime percent of LED reached a saturated value at $33 \%$ with $1.2 \mathrm{~g} / \mathrm{L}$ of CNTs concentration. The extra-lifetime percent of LED almost did not increase with $1.3 \mathrm{~g} / \mathrm{L}$ of CNTs concentration. Thus, we have chosen $1.2 \mathrm{~g} / \mathrm{L}$ for the optimal concentration of CNTs for the 450 W LED floodlight.

\section{Conclusions}

The heat dissipation efficiency of the $450 \mathrm{~W}$ LED floodlight using the MWCNTs nanofluid was examined and evaluated. The temperature of the LED chip was saturated after 40 minutes of working time. By mixing CNTs-OH with $1.2 \mathrm{~g} / \mathrm{L}$ of concentration in the nanofluid, the saturated temperature of LED chip decreased by $4.5^{\circ} \mathrm{C}$ compared to fluid without CNTs. The extra-lifetime percent of LED also reached a saturated value at $33 \%$ with $1.2 \mathrm{~g} / \mathrm{L}$ of optimal CNTs concentration. The experimental results have confirmed the advantage of the MWCNTs based liquid in heat dissipation for $450 \mathrm{~W}$ LED floodlight and other high-power electronic devices.

\section{Conflict of Interests}

The authors declare that there is no conflict of interests regarding the publication of this paper.

\section{Acknowledgments}

The authors acknowledge financial support from the Vietnam National Foundation for Science and Technology Development (NAFOSTED) under Grant no. 103.99-2012.35. The authors also would like to thank the VAST Program for Young Scientist for the financial support (Project no. VAST.ĐLT.05/13-14).

\section{References}

[1] S. U. S. Choi and J. A. Eastman, "Enhancing thermal conductivity of fluids with nanoparticles," in Proceedings of the International Mechanical Engineering Congress and Exhibition, San Francisco, Calif, USA, 1995.

[2] Y.-H. Hung, J.-H. Chen, and T.-P. Teng, "Feasibility assessment of thermal management system for green power sources using nanofluid," Journal of Nanomaterials, vol. 2013, Article ID 321261, 11 pages, 2013.

[3] M. Dong, L. P. Shen, H. Wang, H. B. Wang, and J. Miao, "Investigation on the electrical conductivity of transformer oil-based AlN nanofluid," Journal of Nanomaterials, vol. 2013, Article ID 842963, 7 pages, 2013.

[4] A. M. Hussein, K. V. Sharma, R. A. Bakar, and K. Kadirgama, "The effect of nanofluid volume concentration on heat transfer and friction factor inside a horizontal tube," Journal of Nanomaterials, vol. 2013, Article ID 859563, 12 pages, 2013.

[5] K. Tseng, H. Lee, C. Liao, K. Chen, and H. Lin, "Rapid and efficient synthesis of silver nanofluid using electrical discharge machining," Journal of Nanomaterials, vol. 2013, Article ID 174939, 6 pages, 2013.

[6] V. N. Popov, "Carbon nanotubes: properties and application," Materials Science and Engineering R: Reports, vol. 43, no. 3, pp. 61-102, 2004.

[7] P. N. Minh and P. H. Khoi, "Carbon nanotube: a novel material for applications," Journal of Physics: Conference Series, vol. 187, Article ID 012002, 2009.

[8] S. K. Singhal, M. Lal, Lata, S. R. Kabi, and R. B. Mathur, "Synthesis of $\mathrm{Cu} / \mathrm{CNTs}$ nanocomposites for antimicrobial activity," Advances in Natural Sciences: Nanoscience and Nanotechnology, vol. 3, no. 4, Article ID 045011, 10 pages, 2012.

[9] A. S. Hoang, H. N. Nguyen, H. T. Bui, A. T. Tran, V. A. Duong, and V. B. Nguyen, "Carbon nanotubes materials and their application to guarantee safety from exposure to electromagnetic fields," Advances in Natural Sciences: Nanoscience and Nanotechnology, vol. 4, no. 2, Article ID 025012, 5 pages, 2013.

[10] H. T. Bui, V. C. Nguyen, V. T. Pham, T. T. T. Ngo, and N. M. Phan, "Thermal dissipation media for high power electronic devices using a carbon nanotube-based composite," Advances in Natural Sciences: Nanoscience and Nanotechnology, vol. 2, Article ID 025002, 4 pages, 2011.

[11] N. M. Phan, H. T. Bui, M. H. Nguyen, and H. K. Phan, "Carbonnanotube-based liquids: a new class of nanomaterials and their applications," Advances in Natural Sciences: Nanoscience and Nanotechnology, vol. 5, no. 1, Article ID 015014, 5 pages, 2014.

[12] R. Walvekar, I. A. Faris, and M. Khalid, "Thermal conductivity of carbon nanotube nanofluid-experimental and theoretical study," Heat Transfer-Asian Research, vol. 41, no. 2, pp. 145-163, 2012.

[13] B. H. Thang, P. N. Hong, P. V. Trinh et al., "Simulation of thermal dissipation in a $\mu$-processor using carbon nanotubes 
based composite," Computational Materials Science, vol. 49, no. 4, pp. S302-S306, 2010.

[14] Y. Ding, H. Alias, D. Wen, and R. A. Williams, "Heat transfer of aqueous suspensions of carbon nanotubes (CNT nanofluids)," International Journal of Heat and Mass Transfer, vol. 49, no. 1-2, pp. 240-250, 2006.

[15] B. H. Thang, P. van Trinh, N. van Chuc, P. H. Khoi, and P. N. Minh, "Heat dissipation for microprocessor using multiwalled carbon nanotubes based liquid," The Scientific World Journal, vol. 2013, Article ID 305957, 6 pages, 2013.

[16] N. D. Dung, N. Van Chuc, N. T. T. Tam, N. H. Quang, P. H. Khoi, and P. N. Minh, "Carbon-nanotube growth over iron nanoparticles formed on $\mathrm{CaCO} 3$ support by using hydrogen reduction," Journal of the Korean Physical Society, vol. 52, no. 5, pp. 1372-1377, 2008.

[17] S. Mukherjee and S. Paria, "Preparation and stability of nanofluids-a review," IOSR Journal of Mechanical and Civil Engineering, vol. 9, no. 2, pp. 63-69, 2013.

[18] L. Chen and H. Xie, "Surfactant-free nanofluids containing double- and single-walled carbon nanotubes functionalized by a wet-mechanochemical reaction," Thermochimica Acta, vol. 497, no. 1-2, pp. 67-71, 2010.

[19] S. S. Chougule and S. K. Sahu, "Thermal performance of automobile radiator using carbon nanotube-water nanofluidexperimental study," Journal of Thermal Science and Engineering Applications, vol. 6, no. 4, Article ID 041009, 2014.

[20] B. H. Thang, P. Van Trinh, L. D. Quang, N. T. Huong, P. H. Khoi, and P. N. Minh, "Heat dissipation for Intel core i5 processor using multiwalled carbon nanotubes based ethylene glycol," in Proceedings of the 2nd International Confecence on Advanced Electromaterial (ICAE '13), ICC, Jeju, Republic of Korea, November 2013, Accepted for publication in Journal of Korean Physical Society, 2014. 

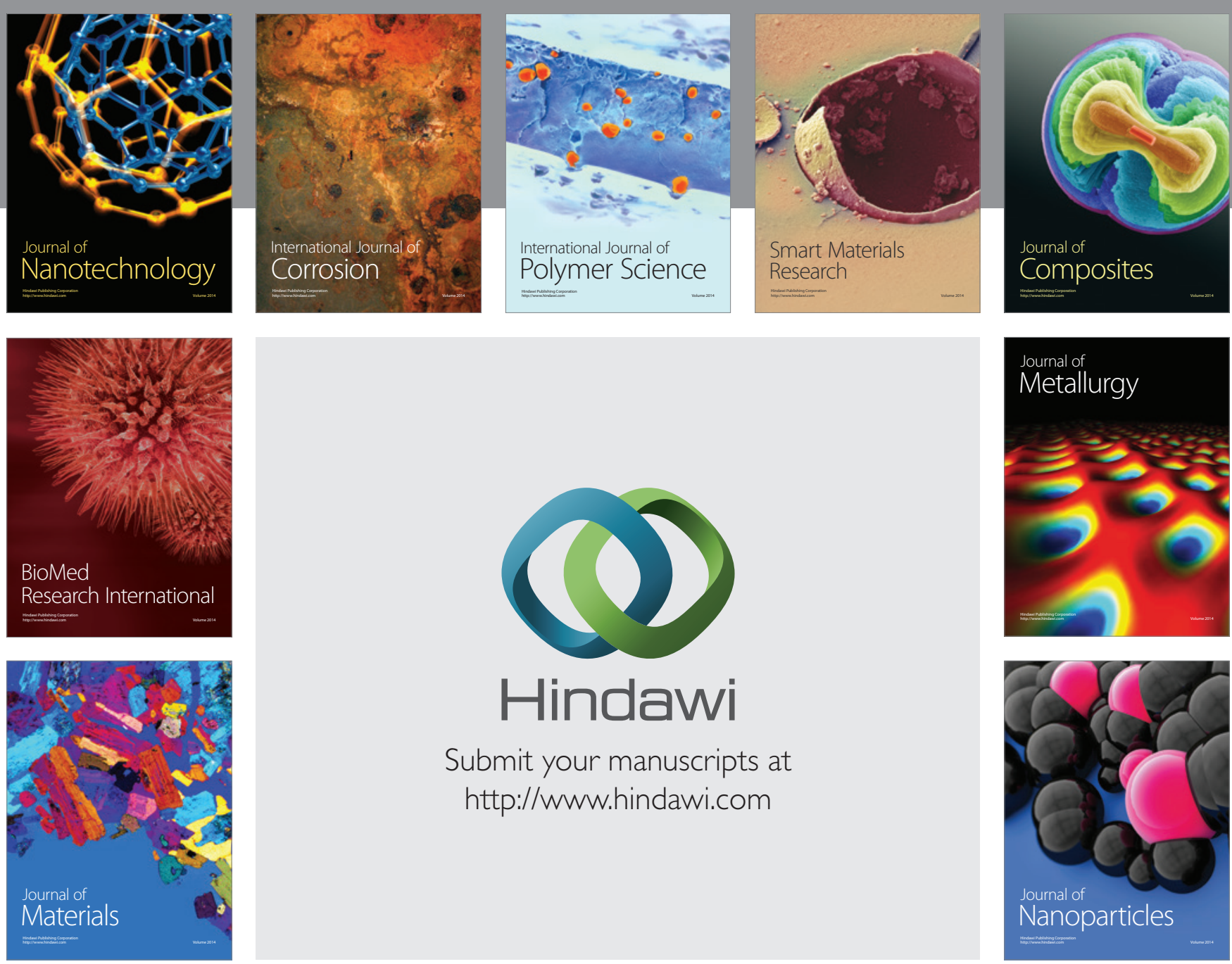

Submit your manuscripts at http://www.hindawi.com
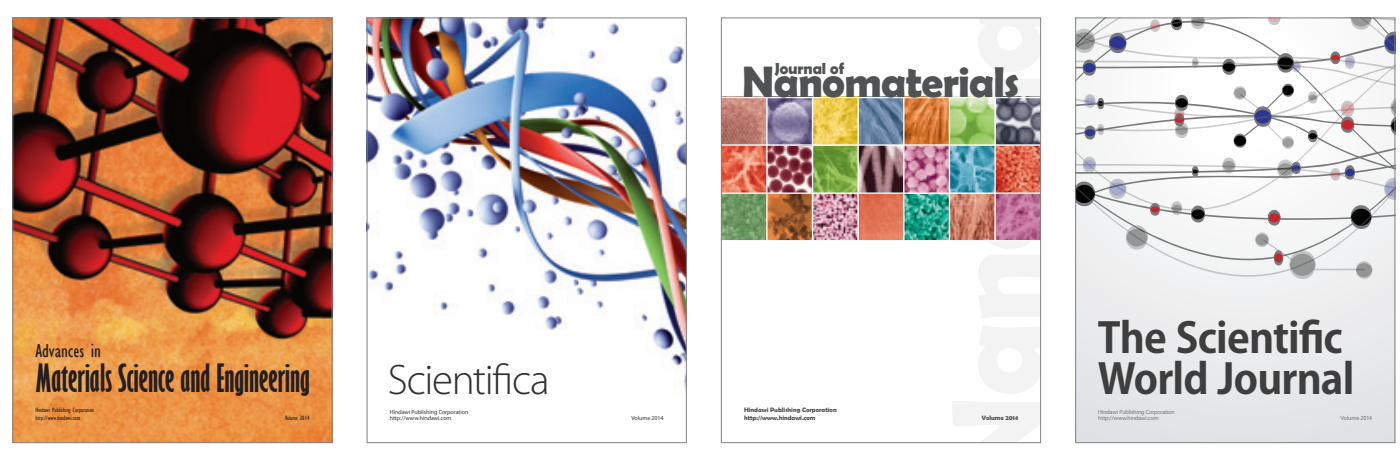

\section{The Scientific World Journal}
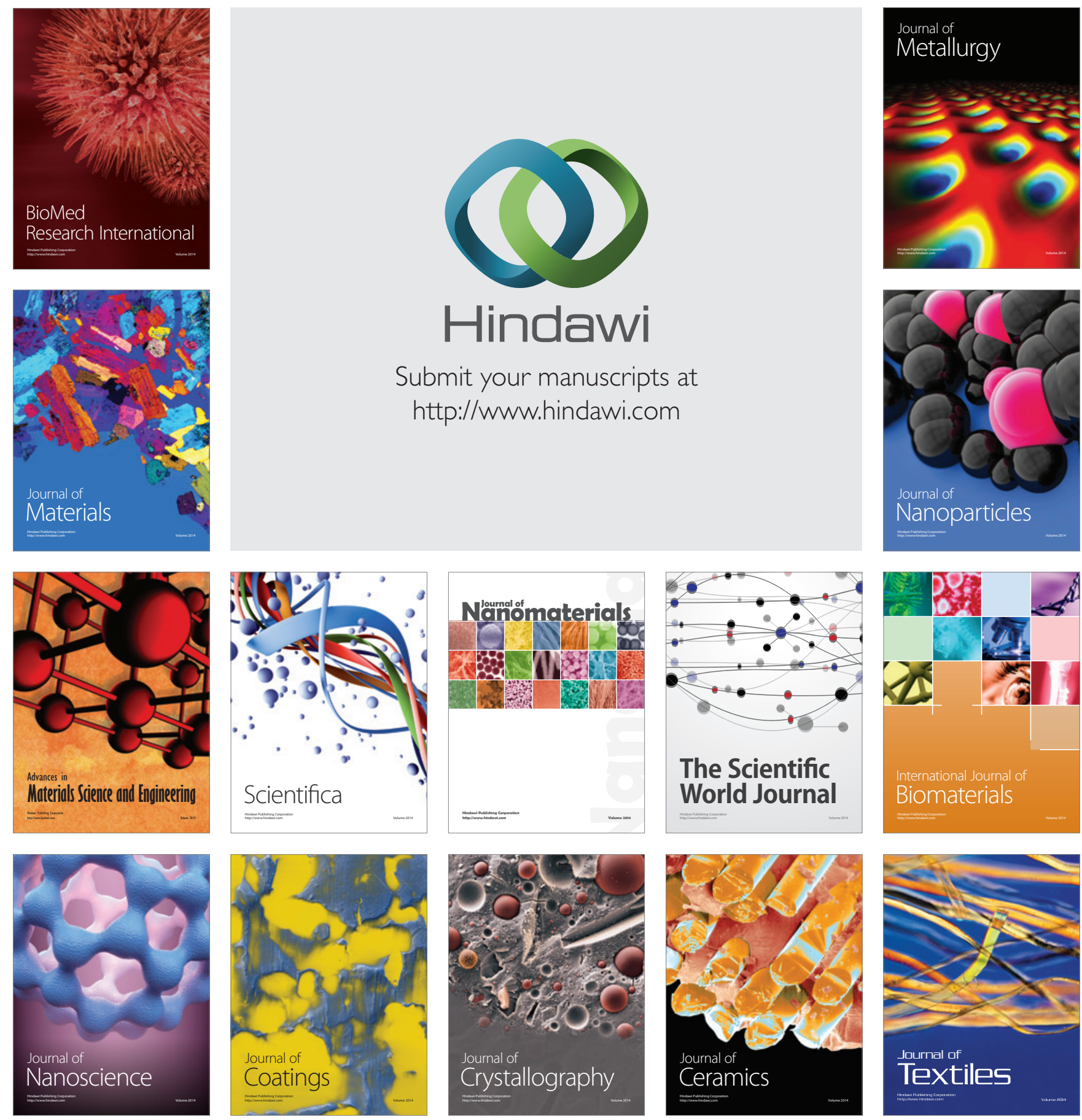